\title{
Assessment of triclosan impact on enzymatic biomarkers in an Indian major carp, Catla catla
}

\author{
Devan Hemalatha ${ }^{1,2}$, Basuvannan Rangasamy', Bojan Nataraj ${ }^{1}$ and Mathan Ramesh ${ }^{\text {* }}$
}

\begin{abstract}
Background: The present study was designed to determine the median lethal concentration (96-h LC50) of triclosan (TCS) and to investigate the effect of a sublethal concentrations of TCS on the activities of glutamic oxaloacetic transaminases (GOT), glutamic pyruvic transaminases (GPT), and glutathione S-transferase (GST) in the gill, liver, and muscle of an Indian major carp Catla catla.
\end{abstract}

Results: In this study, static renewal procedure was followed to determine the $96 \mathrm{LC} 50$ value. The results indicated that the $96-\mathrm{h}$ LC50 of TCS for C. catla was $0.36 \mathrm{mg} \mathrm{L}^{-1}$. 1/10th, 1/25th, and 1/50th of 96-h LC50 value $(0.036,0.014$, $0.007 \mathrm{mg} \mathrm{L}^{-1}$ ) were selected for sublethal studies, and the fish were examined every 5 days for 20 days. The results indicated that TCS exposure to fish at three different sublethal concentrations significantly $(p<0.05, p<0.01)$ enhanced GOT, GPT, and GST enzyme activity in all the tissues with increased dose and exposure period.

Conclusion: Prolonged exposure (20 days) to TCS at sublethal concentrations induces severe physiological alterations in Catla catla, and these biomarkers can be used as a mechanistic tool for evaluating the toxicity-derived alterations in fish.

Keywords: Triclosan, Catla catla, Sublethal, Biomarkers, Glutathione S-transferase, Enzyme

\section{Background}

Triclosan (5-chloro-2-(2,4- dichlorophenoxy) phenol) (TCS), is a common synthetic antimicrobial compound widely used in domestic and consumer care products such as soaps, toothpaste, deodorants, mouthwash, kitchen utensils, textiles, plastics, and medical devices for over 40 years (Hu et al., 2016; Yueh \& Tukey, 2016). TCS exerts its antimicrobial effect by interfering with enoyl-acyl carrier protein reductase (FabI) activity, which is required for fatty acid and biotin biosynthesis. This ultimately leads to the suppression of bacterial growth. Also, TCS destabilizes bacterial membrane by inducing $\mathrm{K}^{+}$leakage (Suller \& Russell, 2000). Dann and Hontela (2011) reported that the worldwide production of TCS has now exceeded 1500 tons per year. Owing to its wide use, and its partial removal from wastewater treatment plants have contributed to its ubiquitous occurrence in various environmental

\footnotetext{
* Correspondence: mathanramesh@yahoo.com

'Unit of Toxicology, Department of Zoology, School of Life Sciences,

Bharathiar University, Coimbatore, Tamil Nadu 641 046, India

Full list of author information is available at the end of the article
}

matrices such as wastewater [8.05 $\left.\mu \mathrm{g} \mathrm{L}^{-1}\right]$ (Lozano, Rice, Ramirez, \& Torrents, 2013), surface water $\left[0.282 \mathrm{~g} \mathrm{~L}^{-1}\right]$ (Sorensen et al., 2015), and sediments $\left[41.7 \mathrm{~g} \mathrm{~kg}^{-1}\right]$ (Peng et al., 2017). Today, TCS is one of the more frequently detected organic micropollutants in the aquatic environment (Huang et al., 2016; Zhang, Niu, \& Wang, 2016).

The frequent detection of TCS in aquatic environments has elicited concern in both the public as well as scientific communities regarding its bioaccumulation and toxicity to aquatic organisms. TCS possesses a relatively high octanol-water partitioning coefficient (log Kow) of 4.8 (Halden \& Paull, 2005) and high organic carbon-water partitioning coefficients $(\log K o c)$ of 3.8-4.0 (Lindström et al., 2002), which can lead to its bioaccumulation in fatty tissues and biomagnification via food chain, ultimately threatening the safety of nontarget organisms (Ding et al., 2017). One of its degradation products, methyl-triclosan (M-TCS), is more persistent and toxic than the parent compound and thus presents a greater potential for bioaccumulation (Rüdel et al., 2013). 
Numerous studies have revealed the presence of TCS in various aquatic organisms. Adolfsson-Erici, Pettersson, Parkkonen, and Sturve (2002) measured TCS levels in the bile of rainbow trout (Oncorhynchus mykiss) exposed to sewage water. TCS concentrations in bile fluid ranged from $0.44-120 \mathrm{mg} \mathrm{kg}^{-1}$ in fish exposed to sewage water. Likewise, Valters et al. (2005) detected TCS in the blood plasma of 13 fish species collected from the Detroit River (750 to $>10,000 \mathrm{pg} \mathrm{g}^{-1} \mathrm{ww}$ ). Low levels of TCS have also been detected in the plasma of wild Atlantic bottlenose dolphins (Tursiops truncates) (Fair et al., 2009) and a killer whale (Orcinus orca) (Bennett, Ross, Huff, Alaee, \& Letcher, 2009). TCS concentrations in plasma ranged from 0.025 to $0.2750 \mathrm{ng} \mathrm{g}^{-1}$ wet weight for the dolphins and $9.0 \mathrm{ng} \mathrm{g}^{-1}$ of wet weight for the killer whale, respectively. Similarly, a pharmacokinetic study determined that significant levels of TCS were widely detected in human body fluids such as urine (Calafat, Ye, Wong, Reidy, \& Needham, 2008), blood plasma (Hovander et al., 2002), and even breast milk (Dayan, 2007). Based on these studies and the possible risk associated with TCS exposure, it is currently classified as a category III compound by the US Food and Drug Administration (Fang et al., 2010), which has recently banned its use in consumer soap (FDA (U.S. Food and Drug Administration), 2016).

Earlier findings have indicated that the TCS is highly toxic to aquatic organisms. It was reported that TCS cause developmental anomalies with embryotoxicity and biochemical changes, bioaccumulation, endocrine disruption, and reproductive effects in Japanese medaka (Foran, Bennett, \& Benson, 2000; Horie, Yamagishi, Takahashi, Iguchi, \& Tatarazako, 2017; Ishibashi et al., 2004) and zebrafish (Falisse, Voisin, \& Silvestre, 2017; Oliveira, Domingues, Grisolia, \& Soares, 2009). In male medaka (Foran et al., 2000), triclosan has been shown to exhibit changes in fin length and sex ratios, suggesting that triclosan has a weak androgenic effect. Furthermore, triclosan has been shown to increase vitellogenin $(\mathrm{Vtg})$ production in male medaka Oryzias latipes (Ishibashi et al., 2004), in male western mosquitofish Gambusia affinis (Raut \& Angus, 2010), and in male Yellow River carp Cyprinus carpio (Wang, Guo, Chen, Sun, \& Fan, 2017a), further suggesting that TCS has significant estrogenic properties. Recent studies have also reported that TCS could induce genotoxic and cytotoxic effects in fish (Capkin, Ozcelep, Kayis, \& Altinok, 2017) and other aquatic organisms (Binelli, Cogni, Parolini, Riva, \& Provini, 2009).

There is strong evidence that TCS could interfere with thyroid hormone (TH)- associated gene expression, accelerate TH-induced metamorphosis, and/or alter larval growth on amphibian (Fort et al., 2011; Helbing, van Aggelen, \& Veldhoen, 2011; Veldhoen et al., 2006), and modulates thyroid homeostasis in fish (Schnitzler et al.,
2016). In male rats, TCS exposure led to decreases in serum testosterone $(\mathrm{T})$, sperm production, and male accessory gland weight (Kumar, Chakraborty, Kural, \& Roy, 2009). Recent studies have also shown that TCS may interfere with thyroid hormone metabolism in humans through the activation of nuclear receptors such as pregnane $\mathrm{X}$ receptor (PXR) and constitutive androstane receptor (CAR) (Yoon et al., 2017). In vitro studies also confirmed that TCS exert both estrogenic and androgenic effects in assays with breast cancer cells (Clayton, Todd, Dowd, \& Aiello, 2011; Gee, Taylor, \& Darbre, 2008) and receptor-based bioassay screens. These adverse effects were thought to be due to the ability of TCS to act as a potential endocrine disruptor in organisms because of its structural similarity to the thyroid hormone thyroxine (T4) and to other known endocrine disruptors, including polychlorinated biphenyls, diethylstilbestrol, and bisphenol A (Ahn et al., 2008).

Numerous studies on the effect of triclosan on several fish species have been investigated; there is virtually no scientific documentation on triclosan's effect on the Indian major carp. Furthermore, measurable levels of TCS were detected in the Kaveri River, Vellar River/estuary, Pichavaram mangrove, and Tamiraparani River in South India (Ramaswamy, Shanmugam, Velu, Rengarajan, \& Larsson, 2011) and it also been detected in the muscle samples of fish Gibelion catla sampled from the Kaveri River, in the range of $0.73-50 \mathrm{ng} / \mathrm{g}$ wet weight (Shanmugam, Ramasamy, Selvaraj, Sampath, \& Ramaswamy, 2014). Hence, the present study used the Indian major carp C. catla to determine the impact of triclosan because $C$. catla is a common inhabitant of freshwater bodies and widely used species for food consumption in India. Measurement of glutamic oxaloacetic transaminases (GOT), glutamic pyruvic transaminases (GPT), and glutathione S-transferase (GST) enzymes have been selected as stress indicators in fish for this study, because these enzymes are considered to be an important serum markers to investigate the health of animal species in concern (Hyne \& Maher, 2003; Ramesh, Anitha, Poopal, \& Shobana, 2018).

\section{Materials and methods \\ Chemicals}

Triclosan (97\% pure; 5-chloro-2-(2,4-dichlorophenoxy) phenol; TCS) and dimethyl sulfoxide $(99.9 \%$ pure; DMSO) were purchased from Sigma-Aldrich, USA. All reagents were of analytical grade.

\section{Test fish and culture conditions}

Fingerlings of Catla catla $(12 \pm 0.25 \mathrm{~g}$ in body weight and $6.3 \pm 0.02 \mathrm{~cm}$ in body length) were netted from Tamil Nadu Fisheries Development Corporation Limited, Aliyar Fish Farm, Tamil Nadu, India. The fish were 
acclimated to the laboratory condition for a month in 350-L fiberglass tanks containing aerated and dechlorinated water, under natural photoperiod conditions (12:12 $\mathrm{h}$ light to dark regime) before the experimentation. During acclimatization and exposure periods, the fish were fed once in a day with rice bran and groundnut oil cake (ad libitum). Each day, dead fish (if occurred) were removed, and $80 \%$ of the water volume was renewed to assure water quality. The physicochemical characteristics of the test water were temperature (25.0 $\left.\pm 1.0^{\circ} \mathrm{C}\right)$, $\mathrm{pH}(7.0 \pm 1)$, salinity $(0.28 \pm 0.1 \mathrm{ppt})$, and total hardness $\left(16.0 \pm 0.5 \mathrm{mg} \mathrm{L}^{-1}\right)$ (American Public Health Association (APHA), 1998). The fish were starved for $24 \mathrm{~h}$ before experimentation to avoid prandial effects during the assay.

\section{Determination of 96-h LC50 of TCS and selection of exposure concentrations}

Acute toxicity tests (96-h duration) were conducted using a static renewal procedure (APHA, AWWA, WPCF, 2005). Test solutions of TCS were prepared by dissolving in dimethyl sulfoxide (DMSO) and further diluted in double distilled water. Prior to the definitive tests, range-finding tests were performed to determine the appropriate concentration ranges for conducting the definitive test (APHA, 1998). For range-finding test, we prepared different concentrations of TCS (data not shown) and control in a 15-L glass tank, with a test volume of $10 \mathrm{~L}$. For each TCS concentration and control, three replicates were made and 10 fish fingerlings were placed in each. Mortality of the fish fingerlings was routinely monitored and recorded. After preliminary range-finding test, the nominal concentration range $\left(0.2,0.25,0.3,0.35\right.$, and $\left.0.4 \mathrm{mg} \mathrm{L}^{-1}\right)$ for the definitive test was selected. Based on the data obtained, the experiment was repeated in triplicate to obtain the 96-h LC50 value of the test chemical for the target species. Mortality was recorded at the end of every $24,48,72$, and $96 \mathrm{~h}$, and dead fish were removed immediately. Behavioral changes were followed closely.

\section{Exposure and experimental design}

A total of 100 fingerlings were used in the sublethal experiment. The sample was divided into four groups (three experimental groups and one control) of 25 fish each in separate 50 -L glass aquaria $(60 \times 30 \times 30 \mathrm{~cm})$ with three replicates. After acclimatization, these fish were exposed to 0.007 (1/50th), 0.014 (1/25th), and 0.036 (1/10th) $\mathrm{mg} \mathrm{L}^{-1}$ of TCS for 20 days. The control experiments were also performed with the addition of carrier solvent alone (DMSO). The exposure was performed semi-statically, and one half of the water in the aquarium was renewed and spiked with the toxin daily.

At regular intervals of sublethal toxicity on days $5,10,15$, and 20, five fish from each group were randomly selected and killed by immersion in melting ice, and the tissues were excised, i.e., the gill, liver, and muscle. Tissues were homogenized by grinding at $4{ }^{\circ} \mathrm{C}$ in $50 \mathrm{mM}$ potassium phosphate buffer (pH 7.0) containing $0.5 \mathrm{mM}$ EDTA. Homogenate was centrifuged at $10.000 \times g$ for $15 \mathrm{~min}$ at $4{ }^{\circ} \mathrm{C}$. The resultant supernatant was used for the estimation of glutamate oxaloacetate transaminase (GOT), glutamate pyruvate transaminase (GPT), and glutathione-S-transferase (GST) enzyme activities. All the enzyme preparation was carried out in a chilled condition.

\section{Enzyme assay}

Biochemical indices including glutamate oxaloacetate transaminase (GOT) and glutamate pyruvate transaminase (GPT) activities in the gill, liver, and muscle have been studied from both control and experimental fish following the method of Reitman and Franckel (1957). Glutathione-S-transferase (GST) activity was estimated using the diagnostic kit supplied by Nanjing Jiancheng Bioengineering Institute, Nanjing City, P.R. China.

\section{Protein estimation}

Protein was estimated spectrophotometrically by the method of Lowry, Rosebrough, Farr, and Randall (1951), using the Folin phenol reagent with bovine serum albumin (BSA) as a standard.

\section{Statistical analysis}

All data in this study were analyzed by SPSS 20.0 and were expressed as a mean \pm standard error (SE). Statistical differences were determined by one-way ANOVA with a post hoc Duncan's multiple range test (DMRT). Values were considered as statistically significant when $p<0.05$ and highly significant when $p<0.01$.

\section{Results}

No mortality was recorded in the controls. The 96-h LC50 value for TCS in C. catla was $0.36 \mathrm{mg} \mathrm{L}^{-1}$, and the 95\% confidence intervals ranged from 0.348 to 0.379 $\mathrm{mg} \mathrm{L}^{-1}$. The risk ranking of TCS is therefore highly toxic (Passino \& Smith, 1987).

The changes in GOT and GPT enzyme activities in tissues (gills, liver, and muscle) of $C$. catla exposed to TCS are given in Figs. 1 and 2. The obtained results revealed that treatment of $C$. catla with TCS induced significant increase in GOT and GPT activity in the gill, liver, and muscle as compared to the control. All these increases are significantly related to the increase of TCS dose through the exposure period (20 days). The lowest levels of GOT and GPT activity were recorded at 5 days in $0.007 \mathrm{mg} \mathrm{L}^{-1}$ of TCS in all tissues, and the levels gradually increased as the experiment progressed. There were also concentration and time-dependent increases in GST activity in all tissues (gill, liver, and muscle) 


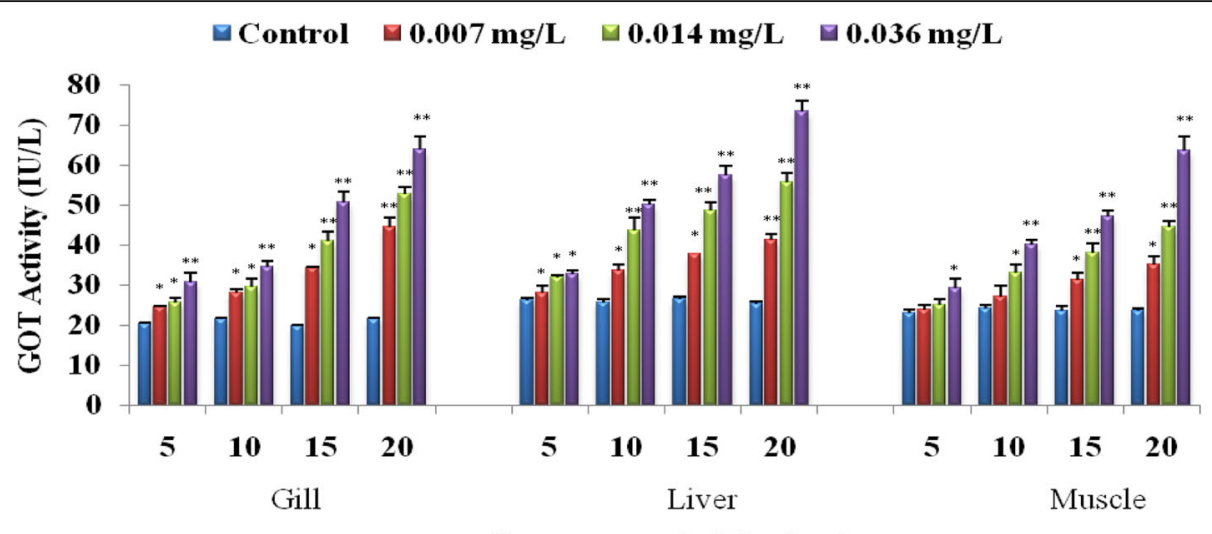

Exposure period (in days)

Fig. 1 Effect of sublethal concentrations of TCS on GOT activity in different tissues of $C$. catla. Values are means \pm SE of five individual observations. Asterisk and double asterisk indicate statistically significant differences from control values at $p<0.05$ and $p<0.01$, respectively

among fish exposed to TCS (Fig. 3). The maximum increase in GST activity was $206.7 \%$ in the case of liver tissue. The increased values of the gill and muscle were of the order of $134.8 \%$ and $78 \%$ when compared with control values.

\section{Discussion}

In the present study, the 96-h LC50 of TCS to C. catla was found to be $0.36 \mathrm{mg} \mathrm{L}^{-1}$, and the $95 \%$ confidence intervals ranged from 0.348 to $0.379 \mathrm{mg} \mathrm{L}^{-1}$. The risk ranking of TCS is therefore highly toxic to fish (Passino \& Smith, 1987). Similar to our results, Oliveira et al. (2009) also reported that the 96-h LC50 of TCS for Danio rerio is $0.34 \mathrm{mg} \mathrm{L}^{-1}$. However, the 96-h LC50 value for TCS to common carp observed in the current study was lower from the results reported by Escarrone, Caldas, Primel, Martins, and Nery (2016) and Wang, Liu, Chen, Xu, and Wang (2017b). In contrast, the 96-h LC50 value for TCS to common carp observed in the present study was higher from the results reported by Liang, Nie, Ying, An, and Li (2013) and Orvos et al. (2002). The variations between their results and ours may result from differences in the age, size, health, and type of species (Abdul-Farah, Ateeq, Ali, \& Ahmad, 2004) and also may be due concentration and formulation of chemical (Nwani et al., 2011). Hence, it is concluded that the toxic nature may depend on species and chemical.

Glutamic oxaloacetic (GOT) and glutamic pyruvic (GPT) transaminases are among many enzymes that are commonly used as biomarkers of environmental pollution (El-Shehawi, Ali, \& Seehy, 2007). Kabeer Ahmad and Rao (1980) reported that transamination and transdeamination reactions are prominent under stress conditions. These two key enzymes are known for their role in the mobilizing L-amino acid for the gluconeogenesis and in the metabolism of carbohydrate and protein. When the cell is damaged, these enzymes are released into the bloodstream, thus making the enzyme level in the blood to go up. Martins,

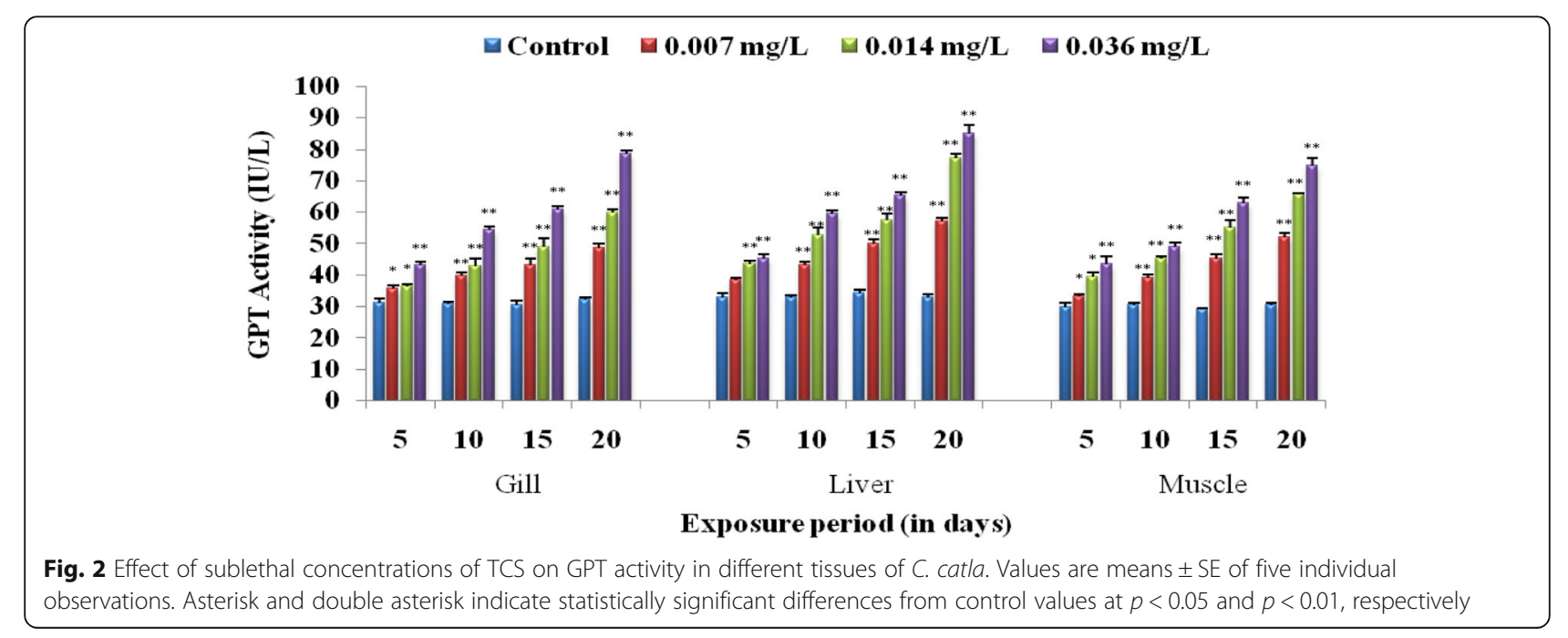




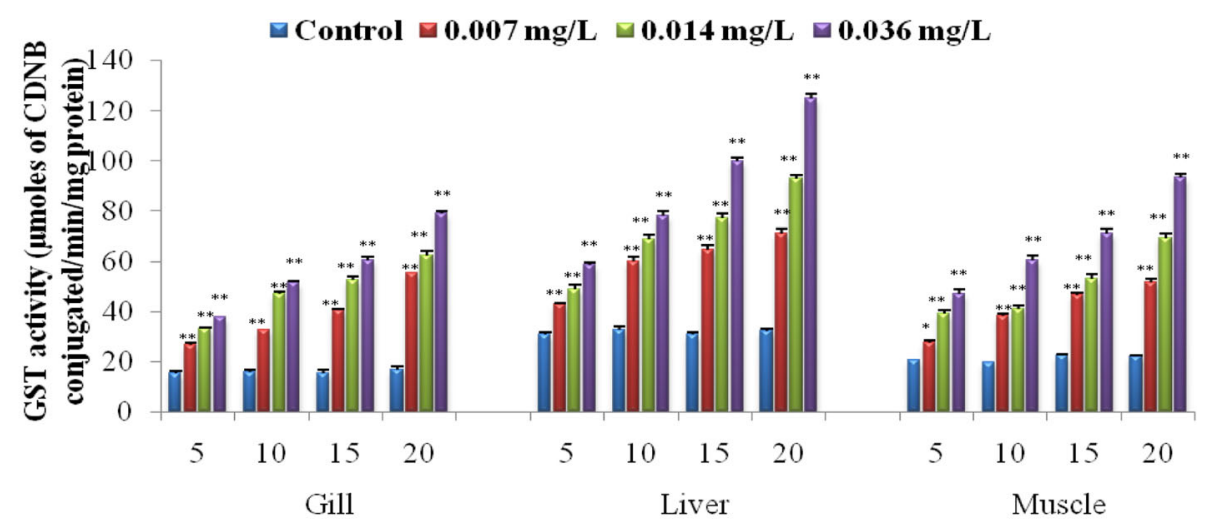

Exposure period (in days)

Fig. 3 Effect of sublethal concentrations of TCS on GST activity in different tissues of C. catla. Values are means \pm SE of five individual observations. Asterisk and double asterisk indicate statistically significant differences from control values at $p<0.05$ and $p<0.01$, respectively

Monteiro, Soares, and Quintaneiro (2017) reported that TCS in the fish liver could be metabolized to toxic intermediates which generate reactive oxygen species (ROS). Increases in intracellular ROS may cause lipid peroxidation (LPO) resulting in an increased permeability of liver cell membrane. As a result, hepatic enzymes including GOT and GPT are released into plasma (Srivastava et al., 2004; Venkateswara Rao, 2006). Likewise, ROS produced from the metabolism of TCS may damage other organs such as the gills, kidney, and muscle, etc., causing the leakage of enzymes into plasma. In this sense, if the cellular injury is chronic, GOT and GPT levels will remain elevated (Banaee, Sureda, Mirvaghefi, \& Ahmadi, 2011). In the present study, the elevation of GOT and GPT activity in the gill, liver, and muscle of TCS-exposed fish indicates the damage of these organs/tissue due to TCS toxicity.

The elevation of transaminases (GOT and GPT) activity in gill, liver and muscle of carbamazepine (CBZ)-exposed fish may be due to organ damage due to drug toxicity (Malarvizhi, Kavitha, Saravanan, \& Ramesh, 2012). Elevation of GOT and GPT activities were also recorded in Labeo rohita exposed to oxytetracycline and $\mathrm{N}$-acetyl-p-aminophenol (Ambili, Saravanan, Ramesh, Abhijith, \& Poopal, 2013; Renuka, Poopal, Ramesh, \& Clara-Bindu, 2018) and in Cyprinus carpio var. Jian exposed to 2,3,7,8-tetrachlorodibenzo-p-dioxin (TCDD) (Du, Cao, Jia, \& Yin, 2017). The increase in GOT and GPT activity in fish may be a mechanism to meet increase energy demand under toxic conditions (Ambili et al., 2013). A change in protein and carbohydrate metabolism during stress condition may also affect the GOT and GPT activity (Reddy \& Venugopal, 1991). Barse et al. (2010) stated that the increase in GPT activity in Cyprinus carpio exposed to methylparaben an antibacterial as well as antifungal agent indicates increased transamination. TCS mainly induces toxic stress in aquatic organisms in the form of non-specific narcosis and specific actions such as membrane destabilization and uncoupling of oxidative phosphorylation (Franz, Altenburger, Heilmaeir, \& Schmidtt-Jansen, 2008; Lyndall et al., 2010).

Glutathione S-transferase (GST) is considered the most important enzyme in the phase II pathway, which involved in xenobiotic detoxification and excretion of xenobiotics and their metabolites (George, 1994; Sheehan, Meade, Foley, \& Dowd, 2001). GST converts xenobiotics to non-toxic metabolites by conjugation with GSH (Halliwell \& Gutteridge, 1989; Hermes-Lima \& Storey, 1993). Increased (Smith \& Litwack, 1980) or inhibited (Oruc, Sevgiler, \& Uner, 2004) activities of GST occurs in several tissues of fish at different exposure periods to inducers, and this depends on the type of tissue and nature of the inducer (Cho \& Kim, 2000; Lamb \& Franklin, 2000). Generally, the GST was more active in the liver tissue than in the gill and muscle, which indicates the effective role of the liver in xenobiotic detoxification process (Basha \& Rani, 2003). A similar tendency in GST activities was observed in fish C. catla after TCS exposure. This indicates the active involvement of this enzyme in detoxification of xenobiotics. The activation of GST activity in TCS-exposed T. japonicas indicates the antioxidant defense system to cope up the oxidative stress (Park, Han, Lee, Seo, \& Lee, 2017). Sahu, Karmakar, Kumar, Shukla, and Kumar (2018) reported that the significant increase in glutathione-S-transferase activity in the gill and liver tissue of Pangasianodon hypophthalmus exposed to triclosan indicates the scavenging of oxygen radicals by the enzymes.

The inducement of antioxidant system in TCS-exposed goldfish Carassius auratus at acute concentration may be beneficial to protect the cells from oxidative damage (Wang, Xu, Zheng, \& Haifang, 2018). Likewise, TCS stimulated the GST activity in mussel digestive gland indicating that TCS may be a substrate for phase II enzymes (Canesi et al., 2007). Such results are 
concordant with the previous reports of the effects of TCS on other species such as zebrafish (Oliveira et al., 2009); swordtail fish (Liang et al., 2013); Daphnia magna (Peng et al., 2013); Yellow Catfish (Ku et al., 2014); copepod (Park et al., 2017); frog (Martins et al., 2017); and Brachionus koreanus ((Han et al., 2016). In contrast to the above, no significant effect on GST activity was noticed at lower concentrations (Falisse et al., 2017; Oliveira et al., 2009). GST mRNA expression was found to be maximum in swordtails exposed to high dose of TCS suggesting that the enzyme played an significant role in detoxifying TCS (Liang et al., 2013). In aquatic organisms, GST produce less toxic and hydrophilic molecules which play a major role to prevent the oxidative damage via the conjugation of the breakdown products of lipid peroxidases to GSH (Fernandes, Fontainhas-Fernandes, Ferreira, \& Salgado, 2008). Hence, the alteration of GST activity can be widely used as a biomarker for the effects caused by xenobiotics (Dourado, Fernandes, Mannervik, \& Romos, 2008).

\section{Conclusions}

The 96-h LC50 of TCS for C. catla was determined to be $0.036 \mathrm{mg} \mathrm{L}^{-1}$. The effects of sublethal concentrations of TCS on stress-mediated enzymes were investigated in the gill, liver, and muscle. In this study, the sublethal concentrations of TCS caused significant changes in the GOT, GPT, and GST activities compared with the control. Thus, these enzymes could be selected as a suitable biomarker to reflect TCS effects in C. catla. Furthermore, this result exhibited that increasing concentration of TCS in the environment causes considerable stress for Indian major carp C. catla, suggesting that TCS is highly toxic to fish.

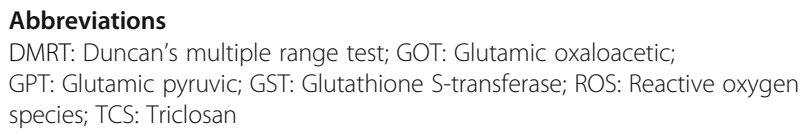

\section{Acknowledgements}

We declare that we have no acknowledgements.

\section{Funding}

There is no funding available for this work.

\section{Availability of data and materials}

Not applicable

\section{Authors' contributions}

$\mathrm{DH}$ designed the overall work and wrote the manuscripts. BR and BN performed to help for the experimental work and also for the calculation part. MR proposed the research idea and made correction in the manuscript. All authors read and approved the final manuscript.

Ethics approval and consent to participate

We declare that we do not need an ethics approval to conduct the experimental work on major carp (Catla catla).

Consent for publication

Not applicable

\section{Competing interests}

The authors declare that they have no competing interests.

\section{Publisher's Note}

Springer Nature remains neutral with regard to jurisdictional claims in published maps and institutional affiliations.

\section{Author details}

'Unit of Toxicology, Department of Zoology, School of Life Sciences, Bharathiar University, Coimbatore, Tamil Nadu 641 046, India. ${ }^{2}$ Department of Zoology, PSG College of Arts \& Science, Coimbatore, Tamil Nadu 641 046, India.

Received: 26 February 2018 Accepted: 2 April 2019

Published online: 29 April 2019

\section{References}

Abdul-Farah, M., Ateeq, B., Ali, M. N., \& Ahmad, W. (2004). Studies on lethal concentrations and toxicity stress of some xenobiotics on aquatic organisms. Chemosphere, 55, 257-265.

Adolfsson-Erici, M., Pettersson, M., Parkkonen, J., \& Sturve, J. (2002). Triclosan, a commonly used bactericide found in human milk and in the aquatic environment in Sweden. Chemosphere, 46, 1485-1489.

Ahn, K. C., Zhao, B. Chen, J., Cherednichenko, G., Sanmarti, E., \& Denison, M. S. (2008). In vitro biologic activities of the antimicrobials triclocarban, its analogs, and triclosan in bioassay screens: Receptor-based bioassay screens. Environmental Health Perspectives, 116, 1203-1210.

Ambili, T. R., Saravanan, M., Ramesh, M., Abhijith, D. B., \& Poopal, R. K. (2013). Toxicological effects of the antibiotic oxytetracycline to an Indian major carp Labeo rohita. Archives of Environmental Contamination and Toxicology, 64, 494-503.

American Public Health Association (APHA) (1998). Standard methods for the examination of water and wastewater, (20th ed., ). Washington, DC: American Public Health Association.

APHA, AWWA, WPCF (2005). Standard methods for the examination of water and waste water $21^{\text {st }}, 401$ edn. Washington, DC: American Public Health Association.

Banaee, M., Sureda, A., Mirvaghefi, A. R., \& Ahmadi, K. (2011). Effects of diazinon on biochemical parameters of blood in rainbow trout (Oncorhynchus mykiss). Pesticide Biochemistry and Physiology, 99, 1-6.

Barse, A. V., Chakrabarti, T., Ghosh, T. K., Pal, A. K., Kumar, N., Raman, R. P., \& Jadhao, S. B. (2010). Vitellogenin induction and histometabolic changes following exposure of Cyprinus carpio to methylparaben. Asian-Australasian Journal of Animal Sciences, 23(12), 1557-1565.

Basha, P. S., \& Rani, A. U. (2003). Cadmium-induced antioxidant defense mechanism in freshwater teleost Oreochromis mossambicus (tilapia). Ecotoxicology and Environmental Safety, 56, 218-221.

Bennett, E. R. Ross, P. S. Huff, D. Alaee, M. \& Letcher, R. J. (2009). Chlorinated and brominated organic contaminants and metabolites in the plasma and diet of a captive killer whale (Orcinus orca). Marine Pollution Bulletin, 58, 1078-1083

Binelli, A., Cogni, D., Parolini, M., Riva, C., \& Provini, A. (2009). In vivo experiments for the evaluation of genotoxic and cytotoxic effects of triclosan in zebra mussel hemocytes. Aquatic Toxicology, 91, 238-244.

Calafat, A. M., Ye, X., Wong, L. Y., Reidy, J. A., \& Needham, L. L. (2008). Urinary concentrations of triclosan in the U.S. population: 2003-2004. Environmental Health Perspectives, 116, 303-307.

Canesi, L., Ciacci, C., Lorusso, L. C., Betti, M., Gallo, G., Pojana, G., \& Marcomini, A. (2007). Effects of triclosan on Mytilus galloprovincialis hemocyte function and digestive gland enzyme activities: Possible modes of action on non target organisms. Comparative Biochemistry and Physiology, Part C, 145, 464-472.

Capkin, E., Ozcelep, T., Kayis, S., \& Altinok, I. (2017). Antimicrobial agents, triclosan, chloroxylenol, methylisothiazolinone and borax, used in cleaning had genotoxic and histopathologic effects on rainbow trout. Chemosphere, 182, $720-729$

Cho, M. K., \& Kim, S. G. (2000). Induction of class alpha glutathione S-transferases by 4-methylthiazole in the rat liver: Role of oxidative stress. Toxicology Letters, $115,107-115$.

Clayton, E. M., Todd, M., Dowd, J. B., \& Aiello, A. E. (2011). The impact of bisphenol a and triclosan on immune parameters in the U.S. population, NHANES 2003-2006. Environmental Health Perspectives, 119, 390-396. 
Dann, A.B., \& Hontela, A. (2011). Triclosan : environmental exposure, toxicity and mechanisms of action. Journal of Applied Toxicology, 31(4), 285-311.

Dayan, A. D. (2007). Risk assessment of triclosan [lrgasan] in human breast milk. Food and Chemical Toxicology, 45, 125-129.

Ding, T., Lin, K., Bao, L., Yang, M., Li, J., Yang, B., \& Gan, J. (2017). Biouptake, toxicity and biotransformation of triclosan in diatom Cymbella sp. and the influence of humic acid. Environmental Pollution, 234, 231-242.

Dourado, D. F., Fernandes, P. A., Mannervik, B., \& Romos, M. J. (2008). Glutathione transferase: New model for glutathione activation. Chemistry, 14, 9591-9598.

Du, J., Cao, L., Jia, R., \& Yin, G. (2017). Hepatoprotective and antioxidant effects of dietary glycyrrhiza polysaccharide against TCDD-induced hepatic injury and RT-PCR quantification of AHR2, ARNT2, CYP1A mRNA in Jian carp (Cyprinus carpio var. Jian). Journal of Environmental Sciences, 51, 181-190.

El-Shehawi, A. M., Ali, F. K., \& Seehy, M. A. (2007). Estimation of water pollution by genetic biomarkers in tilapia and catfish species shows species-site interaction. African Journal of Biotechnology, 6, 840-846.

Escarrone, A. L., Caldas, S. S., Primel, E. G., Martins, S. E., \& Nery, L. E. (2016). Uptake, tissue distribution and depuration of triclosan in the guppy Poecilia vivipara acclimated to freshwater. Science of the Total Environment, 560-561, 218-224.

Fair, P. A., Lee, H. B., Adams, J., Darling, C., Pacepavicius, G., Alaee, M., ... Muir, D. (2009). Occurrence of triclosan in plasma of wild Atlantic bottlenose dolphins (Tursiops truncatus) and in their environment. Environmental Pollution, 157, 2248-2254.

Falisse, E., Voisin, A. S., \& Silvestre, F. (2017). Impacts of triclosan exposure on zebrafish early-life stage: Toxicity and acclimation mechanisms. Aquatic Toxicology, 189, 97-107.

Fang, J. L., Stingley, R. L., Beland, F. A., Harrouk, W., Lumpkins, D. L., \& Howard, P. (2010). Occurrence, efficacy, metabolism, and toxicity of triclosan. Journal of Environmental Science and Health. C: Environmental Carcinogenesis and Ecotoxicology Reviews, 28, 147-171.

FDA (U.S. Food and Drug Administration) (2016). 21 CFR part 310 safety and effectiveness of consumer antiseptics. Topical antimicrobial drug products for over-the-counter human use. Final Rule, Federal Register, 81, 61106-61130.

Fernandes, C., Fontainhas-Fernandes, A., Ferreira, M., \& Salgado, M. A. (2008). Oxidative stress response in gill and liver of Liza saliens, from the EsmorizParamos coastal lagoon, Portugal. Archives of Environmental Contamination and Toxicology, 55, 262-269.

Foran, C. M., Bennett, E. R., \& Benson, W. H. (2000). Developmental evaluation of a potential non-steroidal estrogen: Triclosan. Marine Environmental Research, 50, 153-156.

Fort, D. J., Mathis, M. B., Hanson, W., Fort, C. E., Navarro, L. T., Peter, R., ... Plautz, J. R. (2011). Triclosan and thyroid-mediated metamorphosis in anurans: Differentiating growth effects from thyroid-driven metamorphosis in Xenopus laevis. Toxicological Sciences, 121, 292-302.

Franz, S., Altenburger, R., Heilmaeir, H., \& Schmidtt-Jansen, M. (2008). What contributes to the sensitivity of microalgae to triclosan? Aquatic Toxicology, 90, 102-108.

Gee, R. H., Taylor, C. A., \& Darbre, P. D. (2008). Oestrogenic and androgenic activity of triclosan in breast cancer cells. Journal of Applied Toxicology, 28, 78-91.

George, S. G. (1994). Enzymology and molecular biology of phase II xenobiotics conjugating enzymes in fish. Aquatic Toxicology, 4, 37-85.

Halden, R. U., \& Paull, D. H. (2005). Co-occurrence of triclocarban and triclosan in US water resources. Environmental Science \& Technology, 39, 1420-1426.

Halliwell, B., \& Gutteridge, J. M. C. (1989). Free radicals in biology and medicine, (2nd ed., p. 543). Oxford: Clarendon Press,

Han, J., Won, E. J., Hwang, U. K., Kim, I. C., Yim, J. H., \& Lee, J. S. (2016). Triclosan (TCS) and Triclocarban (TCC) cause lifespan reduction and reproductive impairment through oxidative stress-mediated expression of the defensome in the monogonont rotifer (Brachionus koreanus). Comparative Biochemistry and Physiology C Toxicology and Pharmacology, 185-186, 131-137.

Hyne, R.V. \& Maher, W.A. (2003). Invertebrate biomarkers: links to toxicosis that predict population decline. Ecotoxicology and Environmental Safety, 54, 366-374.

Helbing, C. C., van Aggelen, G., \& Veldhoen, N. (2011). Triclosan affects thyroid hormone-dependent metamorphosis in anurans. Toxicological Sciences, 119, $417-418$.

Hermes-Lima, M., \& Storey, K. B. (1993). In vitro oxidative inactivation of glutathione S-transferase from a freeze tolerant reptile. Molecular and Cellular Biology, 124, 149-158.

Horie, Y., Yamagishi, T., Takahashi, H., Iguchi, T., \& Tatarazako, N. (2017). Effects of triclosan on Japanese medaka (Oryzias latipes) during embryo development early life stage and reproduction. Journal of Applied Toxicology, 38, 544-551.
Hovander, L., Malmberg, T., Athanasiadou, M., Athanassiadis, I., Rahm, S., Bergman, A., \& Wehler, E. K. (2002). Identification of hydroxylated PCB metabolites and other phenolic halogenated pollutants in human blood plasma. Archives of Environmental Contamination and Toxicology, 42, 105-117.

Hu, J., Raikhel, V., Gopalakrishnan, K., Fernandez-Hernandez, H., Lambertini, L., \& Manservisi, F. (2016). Effect of postnatal low-dose exposure to environmental chemicals on the gut microbiome in a rodent model. Microbiome, 4, 26.

Huang, X., Tu, Y., Song, C., Li, T., Lin, J., Wu, Y., ... Wu, C. (2016). Interactions between the antimicrobial agent triclosan and the bloom-forming cyanobacteria Microcystis aeruginosa. Aquatic Toxicology, 172, 103-110.

Ishibashi, H., Matsumura, N., Hirano, M., Matsuoka, M., Shiratsuchi, H., Ishibashi, Y., .. Arizono, K. (2004). Effects of triclosan on the early life stages and reproduction of medaka Oryzias latipes and induction of hepatic vitellogenin. Aquatic Toxicology, 67, 167-179.

Kabeer Ahmad, S. J., \& Rao, K. V. (1980). Toxicity of malathion to the freshwater fish Tilapia mossambicus. Bulletin of Environmental Contamination and Toxicology, 24, 870-874.

Ku, P., Wu, X., Nie, X., Ou, R., Wang, L., Su, T., \& Li, Y. (2014). Effects of triclosan on the detoxification system in the yellow catfish (Pelteobagrus fulvidraco): Expressions of CYP and GST genes and corresponding enzyme activity in phase I, II and antioxidant system. Comparative Biochemistry and Physiology Part C: Toxicology, 166, 105-114.

Kumar, V., Chakraborty, A., Kural, M. R., \& Roy, P. (2009). Alteration of testicular steroidogenesis and histopathology of reproductive system in male rats treated with triclosan. Reproductive Toxicology, 27, 177-185.

Lamb, J. G., \& Franklin, M. R. (2000). Early events in the induction of rat hepatic UDP-glucuronosyl-transferase, glutathione S-transferase and microsomal epoxide hydrolase by 1,7-phenanthroline: Comparison with oltipraz, tertbutyl-4-hydroxyanisole, and tert-butylhydroquinone. Drug Metabolism \& Disposition, 28, 1018-1102.

Liang, X., Nie, X., Ying, G., An, T., \& Li, K. (2013). Assessment of toxic effects of triclosan on the swordtail fish (Xiphophorus helleri) by a multi-biomarker approach. Chemosphere, 90, 1281-1288.

Lindström, A., Buerge, I. J., Poiger, T., Bergqvist, P. A., Muller, M. D., \& Buser, H. R. (2002). Occurrence and environmental behaviour of the bactericide triclosan and its methyl derivative in surface waters and in wastewater. Environmental Science \& Technology, 36, 2322-2329.

Lowry, O. H., Rosebrough, N. J., Farr, A. L., \& Randall, L. (1951). Protein measurement with Folin phenol reagent. The Journal of Biological Chemistry, $193,265-275$

Lozano, N., Rice, C. P., Ramirez, M., \& Torrents, A. (2013). Fate of triclocarban, triclosan and methyltriclosan during wastewater and biosolids treatment processes. Water Research, 47, 4519-4527.

Lyndall, J., Fuchsman, P., Bock, M., Barber, T., Lauren, D., Leigh, K., ... Capdevielle, M. (2010). Probabilistic risk evaluation for triclosan in surface water, sediments, and aquatic biota tissues. Integrated Environmental Assessment and Management, 6(3), 419-440.

Malarvizhi, A., Kavitha, C., Saravanan, M., \& Ramesh, M. (2012). Carbamazepine (CBZ) induced enzymatic stress in gill, liver and muscle of a common carp, Cyprinus carpio. Journal of King Saud University - Science, 24, 179-186.

Martins, D., Monteiro, M. S., Soares, A. M., \& Quintaneiro, C. (2017). Effects of 4-MBC and triclosan in embryos of the frog Pelophylax perezi. Chemosphere, 178, 325-332.

Nwani, C. D., Nagpure, N. S., Kumar, R., Kushwaha, B., Kumar, P., \& Lakra, W. S. (2011). Mutagenic and genotoxic assessment of atrazine-based herbicide to freshwater fish Channa punctatus (Bloch) using micronucleus test and single cell gel electrophoresis. Environmental Toxicology and Pharmacology, 31, 314-322.

Oliveira, R., Domingues, I., Grisolia, C. K., \& Soares, A. (2009). Effects of triclosan on zebrafish early-life stages and adults. Environmental Science and Pollution Research, 16, 679-688.

Oruc, E. O., Sevgiler, Y., \& Uner, N. (2004). Tissue-specific oxidative stress responses in fish exposed to 2,4-D and azinphosmethyl. Comparative Biochemistry and Physiology, 137, 43-51.

Orvos, D. R., Versteeg, D. J., Inauen, J., Capdevielle, M., Rothenstein, A., \& Cunningham, V. (2002). Aquatic toxicity of triclosan. Environmental Toxicology and Chemistry, 21, 13381-13349.

Park, J. C., Han, J., Lee, M. C., Seo, J. S., \& Lee, J. S. (2017). Effects of triclosan (TCS) on fecundity, the antioxidant system, and oxidative stress-mediated gene expression in the copepod Tigriopus japonicus. Aquatic Toxicology, 189, 16-24.

Passino, D. R. M., \& Smith, S. B. (1987). Acute bioassays and hazard evaluation of representative contaminants detected in great lakes fish. Environmental Toxicology and Chemistry, 6, 901-907. 
Peng, X. Z., Xiong, S. S., Qu, W. H., Wang, Z. F., Tan, J. H., Jin, J. B., ... Fan, Y. J. (2017). Persistence, temporal and spatial profiles of ultraviolet absorbents and phenolic personal care products in riverine and estuarine sediment of the Pearl River catchment, China. Journal of Hazardous Materials, 323(Pt A), 139-146.

Peng, Y., Luo, Y., Nie, X. P., Liao, W., Yang, Y. F., \& Ying, G. G. (2013). Toxic effects of triclosan on the detoxification system and breeding of Daphnia magna. Ecotoxicology, 22, 1384-1394.

Ramaswamy, B. R., Shanmugam, G., Velu, G., Rengarajan, B., \& Larsson, D. G. (2011). GC-MS analysis and ecotoxicological risk assessment of triclosan, carbamazepine and parabens in Indian rivers. Journal of Hazardous Materials, 186, 1586-1593.

Ramesh, M., Anitha, S., Poopal, R. K., \& Shobana, C. (2018). Evaluation of acute and sublethal effects of chloroquine $(\mathrm{C} 18 \mathrm{H} 26 \mathrm{CIN} 3)$ on certain enzymological and histopathological biomarkers responses of a freshwater fish Cyprinus carpio. Toxicology Reports, 5, 18-27.

Raut, S. A., \& Angus, R. A. (2010). Triclosan has endocrine-disrupting effects in male western mosquitofish, Gambusia affinis. Environmental Toxicology and Chemistry, 29, 1287-1291.

Reddy, S. L. N., \& Venugopal, N. B. R. K. (1991). In vivo effects of cadmium chloride on certain aspects of protein metabolism in tissues of a freshwater field crab, Barytelphusa guerini. Bulletin of Environmental Contamination and Toxicology, 46, 583-590.

Reitman, S., \& Franckel, S. (1957). A colorimetric method for the determination of serum glutamic oxalo acetic and glutamic pyruvic transaminase. American Journal of Clinical Pathology, 28, 56-63.

Renuka, S., Poopal, R. K., Ramesh, M., \& Clara-Bindu, F. (2018). Responses of Labeo rohita fingerlings to $\mathrm{N}$-acetyl-p-aminophenol toxicity. Ecotoxicology and Environmental Safety, 157, 73-80.

Rüdel, T., Bohmer, W., Müller, M., Fliedner, A., Ricking, M., Teubner, D., \& SchröterKermani, C. (2013). Retrospective study of triclosan and methyl-triclosan residues in fish and suspended particulate matter: Results from the German Environmental Specimen Bank. Chemosphere, 91, 1517-1524.

Sahu, V. K., Karmakar, S., Kumar, S., Shukla, S. P., \& Kumar, K. (2018). Triclosan toxicity alters behavioral and hematological parameters and vital antioxidant and neurological enzymes in Pangasianodon hypophthalmus (Sauvage, 1878). Aquatic Toxicology, 202, 145-152.

Schnitzler, J. G., Frederich, B., Dussenne, M., Klaren, P. H., Silvestre, F., \& Das, K. (2016). Triclosan exposure results in alterations of thyroid hormone status and retarded early development and metamorphosis in Cyprinodon variegatus. Aquatic Toxicology, 181, 1-10.

Shanmugam, G., Ramasamy, K., Selvaraj, K. K., Sampath, S., \& Ramaswamy, B. R. (2014). Triclosan in fresh water fish Gibelion catla from the Kaveri River, India, and its consumption risk assessment. Environmental Forensics, 15, 207-212.

Sheehan, D., Meade, G., Foley, V. M., \& Dowd, C. A. (2001). Structure, function and evolution of glutathione transferases: Implications for classification of nonmammalian members of an ancient enzyme superfamily. Biochemistry Journal, 360, 1-16.

Smith, J., \& Litwack, G. (1980). Roles of ligandin and the glutathione S-transferases in binding steroid metabolites, carcinogens and other compounds. Review in Biochemistry Toxicology, 2, 1-47.

Sorensen, J. P. R., Lapworth, D. J., Nkhuwa, D. C. W., Stuart, M. E., Gooddy, D. C., Bell, R. A., ... Pedley, S. (2015). Emerging contaminants in urban groundwater sources in Africa. Water Research, 72, 51-63.

Srivastava, A. S., Oohara, I., Suzuki, T., Shenouda, S., Singh, S. N., Chauhan, D. P., \& Carrier, E. (2004). Purification and properties of cytosolic alanine aminotransferase from the liver of two freshwater fish, Clarias batrachus and Labeo rohita. Comparative Biochemistry and Physiology - Part B, 137, 197-207.

Suller, M. T., \& Russell, A. D. (2000). Triclosan and antibiotic resistance in Staphylococcus aureus. Journal of Antimicrobial Chemotherapy, 46, 11-18.

Valters, K., Li, H., Alaee, M., D'Sa, I., Marsh, G., Bergman, A., \& Letcher, R. J. (2005). Polybrominated diphenyl ethers and hydroxylated and methoxylated brominated and chlorinated analogues in the plasma of fish from the Detroit River. Environmental Science \& Technology, 39, 5612-5619.

Veldhoen, N., Skirrow, R. C., Osachoff, H., Wigmore, H., Clapson, D. J., Gunderson, M. P., ... Helbing, C. C. (2006). The bactericidal agent triclosan modulates thyroid hormone associated gene expression and disrupts postembryonic anuran development. Aquatic Toxicology, 80, 217-227.

Venkateswara Rao, J. (2006). Sublethal effects of an organophosphorus insecticide (RPR-II) on biochemical parameters of tilapia, Oreochromis mossambicus. Comparative Biochemistry and Physiology - Part C: Toxicology, 143, 492-498.

Wang, F., Guo, X., Chen, W., Sun, Y., \& Fan, C. (2017). Effects of triclosan on hormones and reproductive axis in female Yellow River carp (Cyprinus carpio): Potential mechanisms underlying estrogen effect. Toxicology and Applied Pharmacology, 336, 49-54.

Wang, F., Liu, F., Chen, W., Xu, R., \& Wang, W. (2017). Effects of triclosan (TCS) on hormonal balance and genes of hypothalamus-pituitary- gonad axis of juvenile male Yellow River carp (Cyprinus carpio). Chemosphere, 193, 695-670.

Wang, F., Xu, R., Zheng, F., \& Haifang, L. (2018). Effects of triclosan on acute toxicity, genetic toxicity and oxidative stress in goldfish (Carassius auratus). Experimental Animals, 67(2), 219-227.

Yoon, D. S., Choi, Y., Cha, D. S., Zhang, P., Choi, S. M., Alfhili, M. A., ... Lee, M. H. (2017). Triclosan disrupts SKN-1/Nrf2-mediated oxidative stress response in C. elegans and human mesenchymal stem cells. Scientific Reports, 7, 12592.

Yueh, M. F., \& Tukey, R. H. (2016). Triclosan: A widespread environmental toxicant with many biological effects. Annual Review of Pharmacology and Toxicology, 56, 251-272.

Zhang, L., Niu, J., \& Wang, Y. (2016). Full life-cycle toxicity assessment on triclosan using rotifer Brachionus calyciflorus. Ecotoxicology and Environmental Safety, 127, 30-35.

\section{Submit your manuscript to a SpringerOpen ${ }^{\odot}$ journal and benefit from:}

- Convenient online submission

- Rigorous peer review

- Open access: articles freely available online

- High visibility within the field

- Retaining the copyright to your article

Submit your next manuscript at $>$ springeropen.com 